\title{
Modeling and Simulation of Light Flicker meter
}

\section{using MATLAB}

\author{
Roshani Supriya.B.N ${ }^{1}$, Nayana.P.Shetty ${ }^{2}$ \\ M.Tech Student, Microelectronics and Control Systems, NMAM Institute of Technology, Udupi, India ${ }^{1}$ \\ Associate Professor, Electrical and Electronics Department, NMAM Institute of Technology, Udupi, India ${ }^{2}$
}

\begin{abstract}
The modeling of the alternative flicker meter is based on the original Flicker meter proposed by the IEC61000-4-15. Some important modifications are added in order to quantify the light variations directly. It eliminates the effect associated with the different lamp technologies available through the correct quantification of flicker severity. In order to achieve this objective blocks 1 and 3 of the original IEC Flicker meter has been altered and block 2 is completely eliminated. This article helps in technical computation of alternative flicker meter before going to the hardware implementation using MATLAB simulink.
\end{abstract}

Index Terms:Flicker, Flicker meter, Incandescent Lamp(IL), Cathode Fluorescent Lamp(CFL), Light Emitting Diode (LED).

\section{NOMENCLATURE}

Photo Epilepsy: It is a phenomenon of repetitive changes in brightness of the lamp and their geometric patterns which causes abnormal activities of cells in the brain, its consciousness and also body sensations.

Lamp Eye Brain Model : The model which is used to predict flicker severity curves for lamp technologies.

\section{INTRODUCTION}

FLICKER is a phenomenon of variation in brightness of the lamp due to voltage fluctuations which repeatedly changes over time[2]. This phenomenon causes visual tiredness, headache and loss of concentration in many individuals[1]. The study shows that one in 4000 individual is suffered due to photosensitive epilepsy[2]. The phenomenon of flicker takes place due to the variation in lamp luminous when it is continuously subjected to voltage fluctuation[1].Large power load such as cooling loads and arc furnaces[3] causes some rapid and abrupt alteration resulting into voltage fluctuations in lamp.

This variation in the lamp brightness effects the human eye. Flicker meter is the device which measures the flicker of different lamp technologies. IEC61000-4-15 proposed the standard flicker meter which allows the direct quantification of the flicker in both incandescent and non incandescent bulbs, but the results obtained from non incandescent bulbs is found to be unsatisfactory. This encourages for modeling of a new alternative flicker meter(AFL) using MATLAB simulink which helps to detect flicker in non incandescent bulbs. In order to overcome this limitation block 2 of IEC flicker meter is completely eliminated and modification are done in block 1 and 3.

\section{SIMULATION}

A. Standard IEC Flicker meter

The flickering is due to the voltage fluctuation present in the fundamental voltage and frequency (here we consider the fundamental voltage and frequency as $230 \mathrm{~V}$ and $50 \mathrm{~Hz}$ ). The main parameter which are responsible for the fluctuation are fluctuating frequency[Fm] and amplitude modulation $[\mathrm{M}]$. When these voltage fluctuation $(\mathrm{V})$ applied incandescent lamp of 60 Watt as shown in figure 1 . The waveform of illumination produced is [lux].

The figure 2 shows the block diagram IEC flicker meter. The input 1 to the flicker meter is fluctuated voltage signal. The block A digitalize and normalizes the voltage signal and hence the input to the block B is normalized fluctuated voltage. In block 2 the signal undergo some quadratic operations so as to produce the illumination which is equal to that of IL. This are filtered using low pass filter(LPF) and high pass filter(HPF) to eliminate high frequency and DC component. Block $\mathrm{C}$ is associated to the memory effect of the brain, where squaring is to make fine adjustments and smoothing is to identify the signal felt by the brain. Finally in block D statistical analysis is made to check the severity of the flicker produced. 

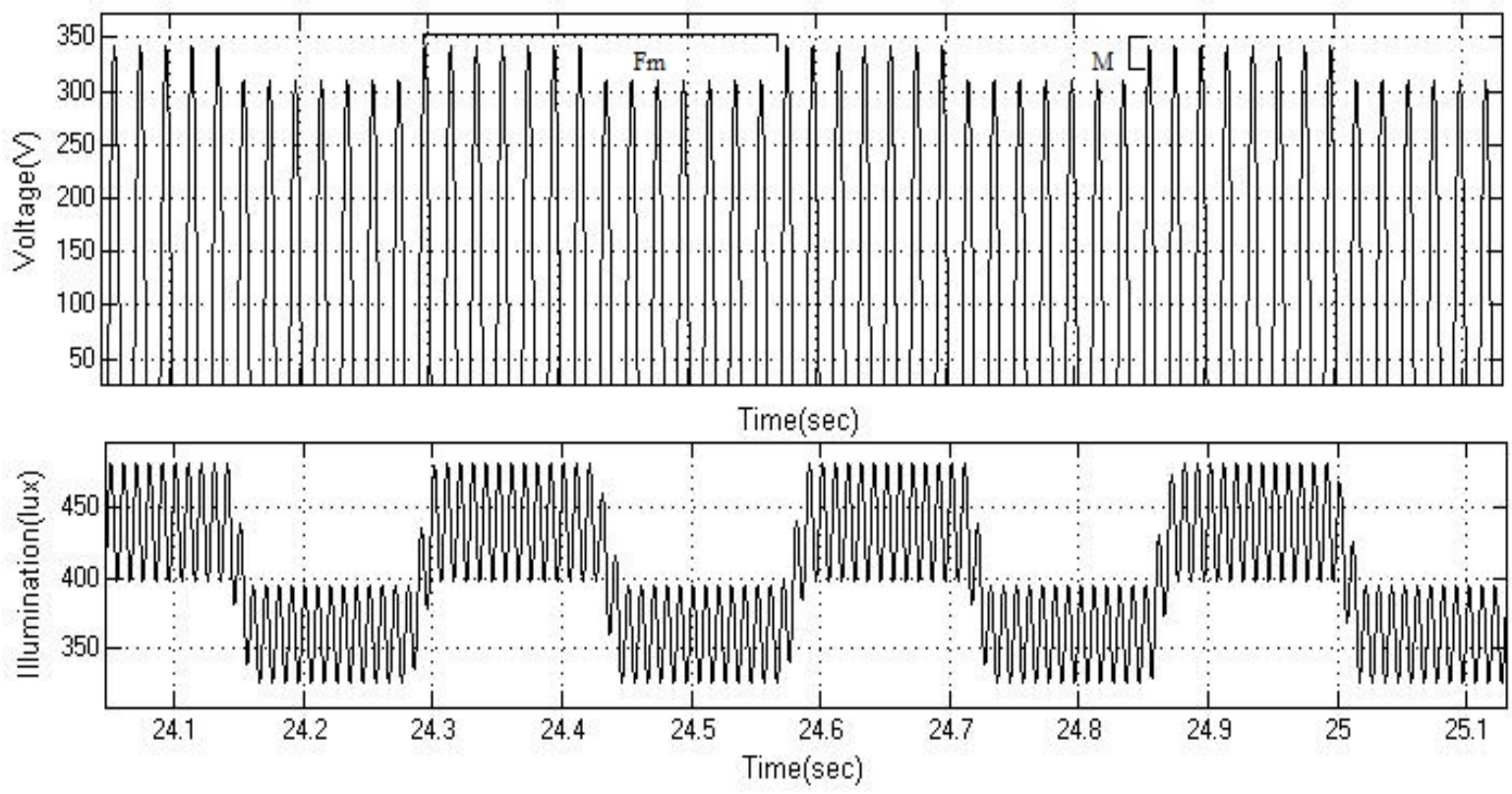

Fig. 1: Waveform of Fluctuated Voltage

i) $\mathrm{Fm}=3.5 \mathrm{~Hz}$ and $\mathrm{M}=5 \%$ and its rms value $\mathrm{V}$

ii) Illumination when submitted to fluctuation of $\mathrm{V}$

LAMP.EEE-BRANEMULATION

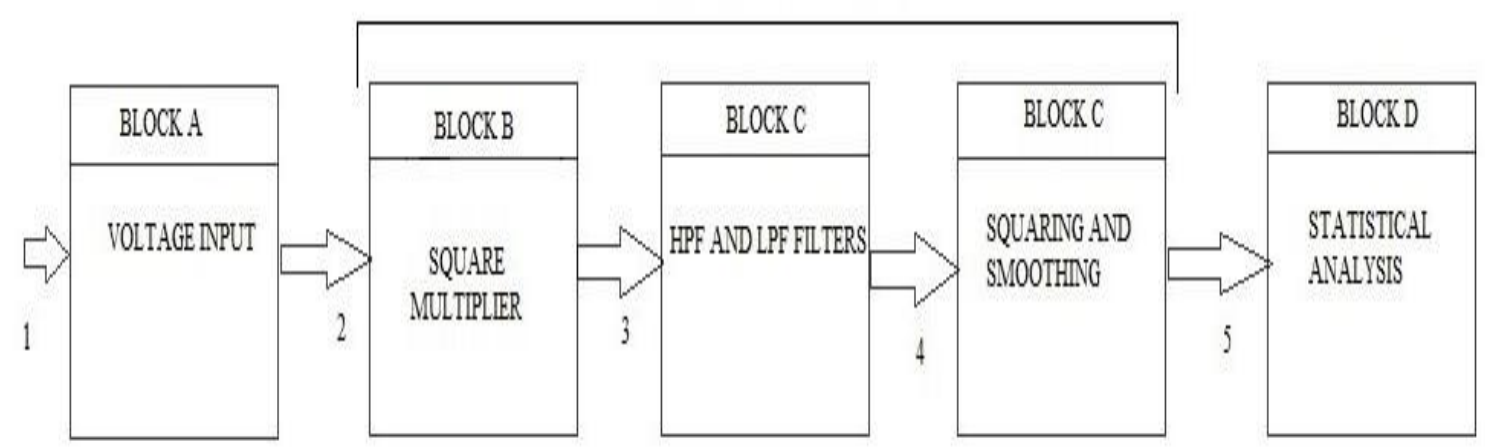

Fig. 2: Block Diagram of IEC Flicker meter

\section{B. Problem Statement}

After the analysis made through different lamp technologies, IEC flicker meter is found to produce satisfactory results only for incandescent lamps. But nowadays these are substituted by non-incandescent lamps such as cathode florescent lamps and LED bulbs which are cost effective with lesser power consumption. IEC Flicker meter is failed to reach the value specified by indicator[3] for non incandescent bulbs.

C. Lamp Modeling

The figure 3 shows model of an IL Lamp. The fundamental voltage supply of $230 \mathrm{~V}$ and $50 \mathrm{~Hz}$ is subjected to voltage fluctuation of frequency(Fm) $3.5 \mathrm{~Hz}$ and amplitude (M) $5 \%$. Current and resistor value depends on the number of watts on the bulb.

- 60 watts of bulb required $184 \mathrm{~mA}$ and $1.7 \mathrm{k}$ ohm amount of current and resistance.

- $\quad$ Resistance $=$ Voltage $(\mathrm{V}) /$ Current $(\mathrm{A})$

- Power converted to lumens which is given by

- $\quad$ Illumination $(\mathrm{Lm})=\operatorname{Power}(\mathrm{W}) *$ illumination per watt $(\mathrm{Lm} / \mathrm{W})$

- Typically, 60W IL gives the illumination of $480 \mathrm{Lm}$

- Therefore 1 watt IL gives the illumination of $8 \mathrm{Lm} / \mathrm{Watt}$

- Average of all the values of illumination is taken as input the flicker meter 


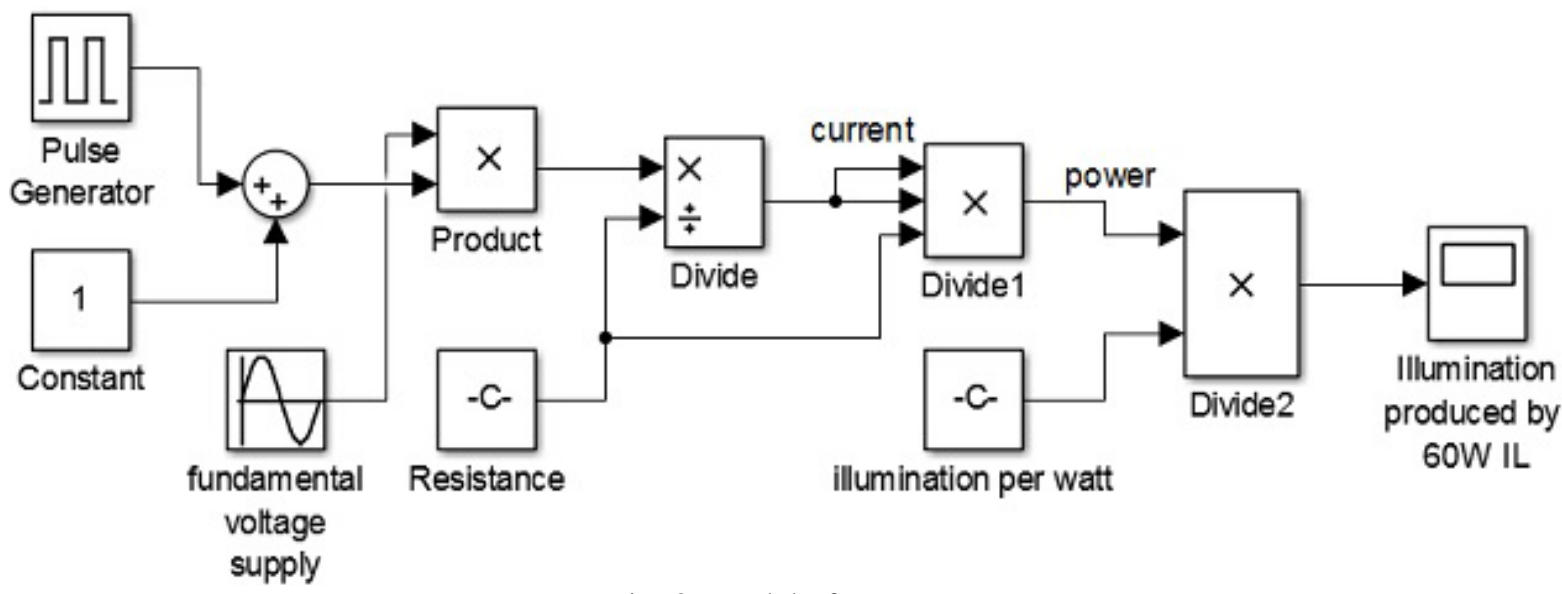

Fig. 3: Model of IL Lamp

D. Modeling of Light Flicker meter

The figure 4 shows model of Alternate Flicker meter. The illumination is converted to voltage with the help of the sensor. Sensor modeling is done in subsystem by considering the characteristics of ISL29101(which is human eye sensitive sensor).Here we make use of butter worth low pass filter of sixth order in order to ensure the linearity of the pass band signal. Analog to digital converter is used to operate the processing under a resolution of $12 \mathrm{bits}$ and sampling rate of $2400 \mathrm{~Hz}$.

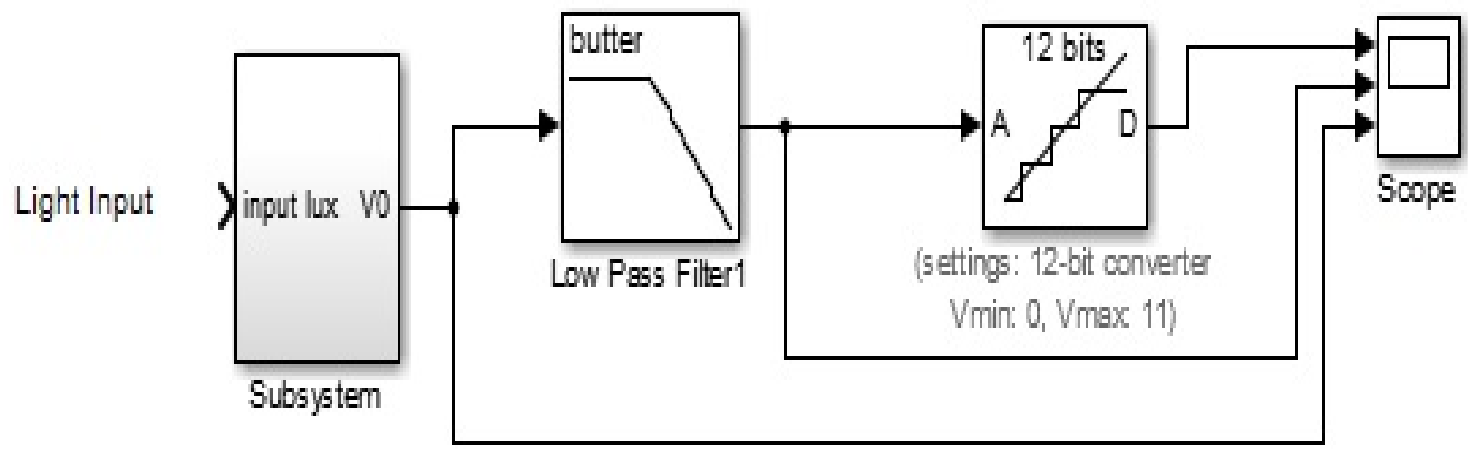

Fig. 4: Model of Alternate Flicker meter

HPF of 1st order with the cutoff frequency of $0.05 \mathrm{~Hz}$ is used to eliminate the dc level. LPF of sixth order with cutoff frequency $42 \mathrm{~Hz}$ helps to eliminate the high frequency component. Smoothing of the signal which is related to the effect of brain memory is done using LPF of 1st order. Scaling helps to make fine adjustment in the output amplitude. The output equals the instantaneous flicker noted by an individual.

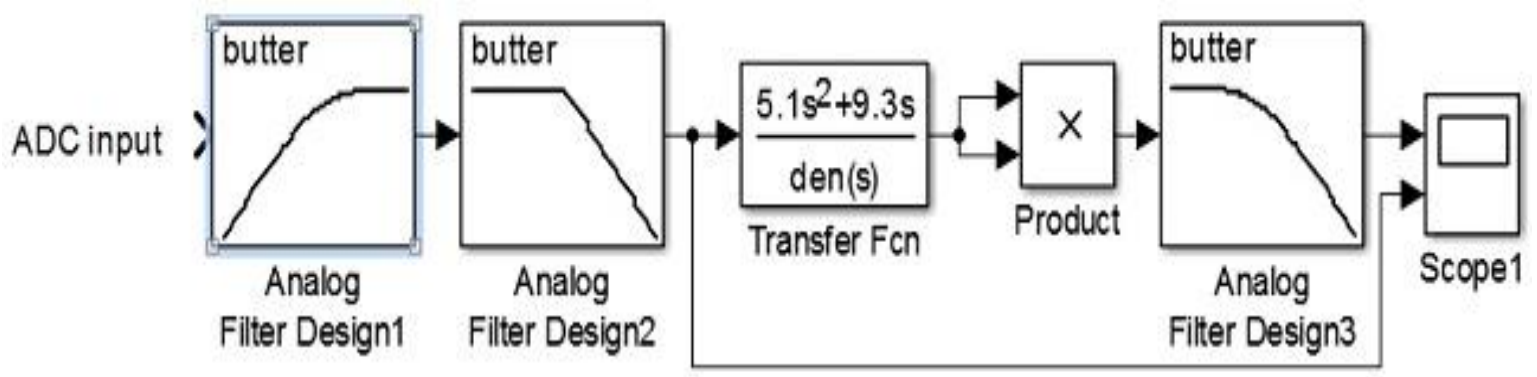

Fig. 5: Model of Alternate Flickermeter(continue)

E. Simulated Results

1. Illuminance of IL OF $60 \mathrm{~W}$ (figure 6)subjected to the rectangular fluctuation of

a) $3.5 \mathrm{~Hz}$ and $5 \%$

b) Demodulated and weighted signal

c) Instantaneous flicker 




a time $(\mathrm{sec})$
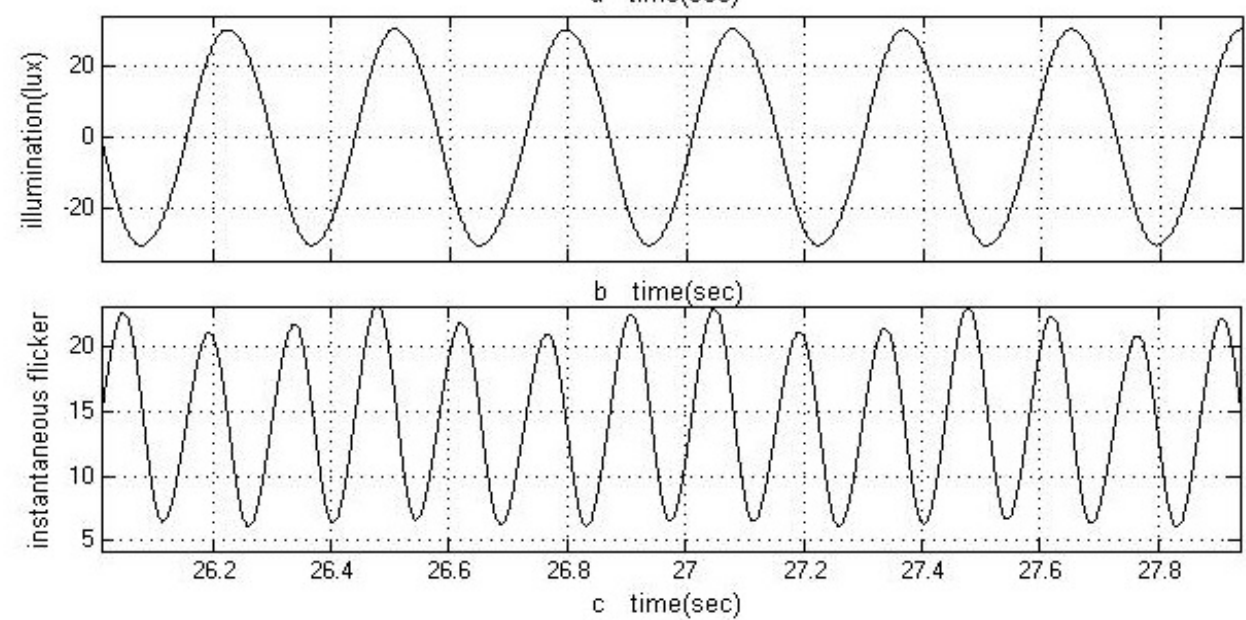

Fig. 6: Result1

1. Illumination of CFL OF $12 \mathrm{~W}$ (figure 7) subjected to the rectangular fluctuation of

a) $3.5 \mathrm{~Hz}$ and $5 \%$

b) Demodulated and weighted signal

c) Instantaneous flicker

2. Illuminance of LED OF 9W(figure 8) subjected to the rectangular fluctuation of

a) $3.5 \mathrm{~Hz}$ and $5 \%$

b) Demodulated and weighted signal

c) Instantaneous flicker
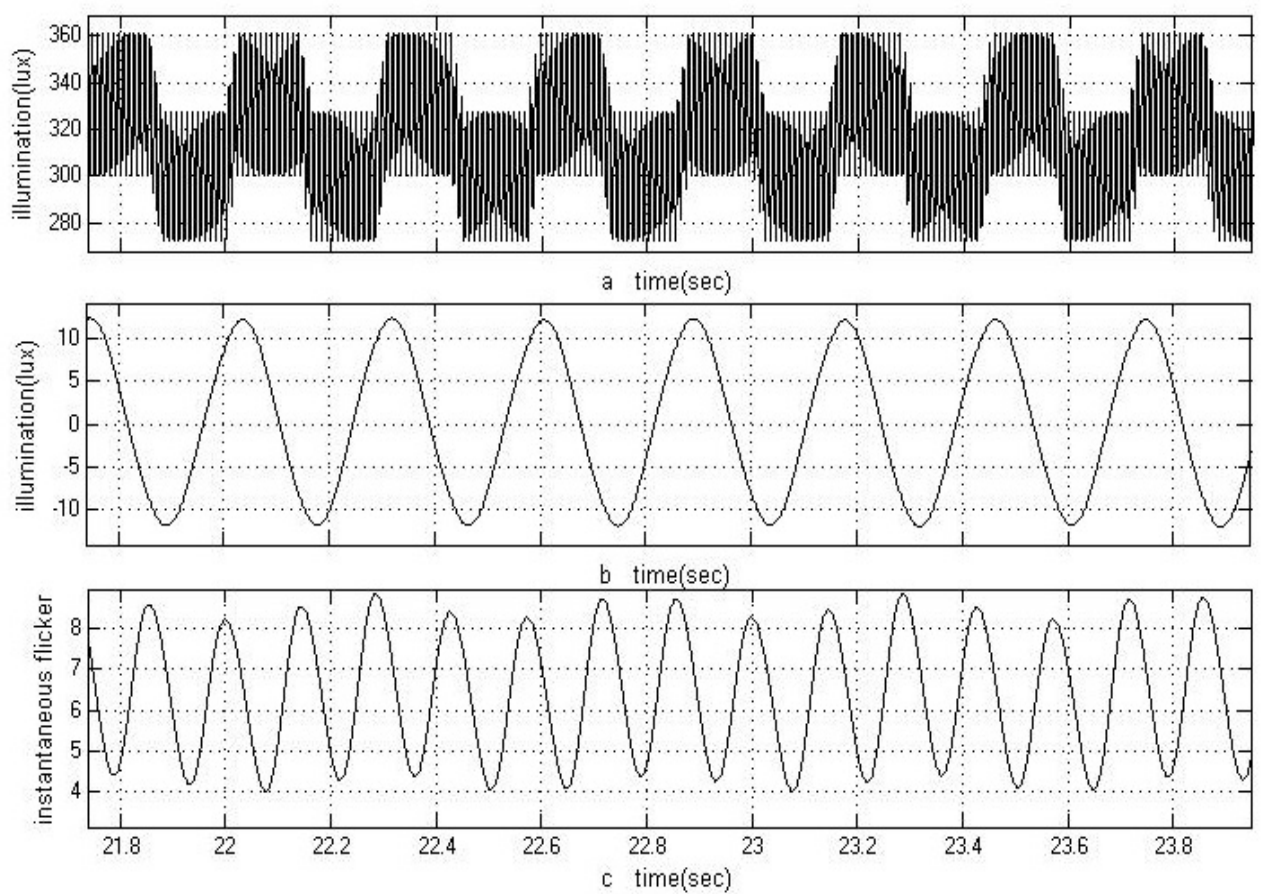

Fig. 7: Result2 
Vol. 4, Special Issue 2, April 2016

IV. CONCLUSION

In order to overcome the limitation of IEC flicker meter, alternate flicker meter is introduced. This helps to measure the flicker curves not only in IL lamps but also in LED and CFL. Hardware requirement for this modeling is cost effective and hence can be used for daily industrial and residential purpose to check the flicker severity. this helps to minimize the power consumption with use of appropriate lamps and also overcomes many health related to light flicker.
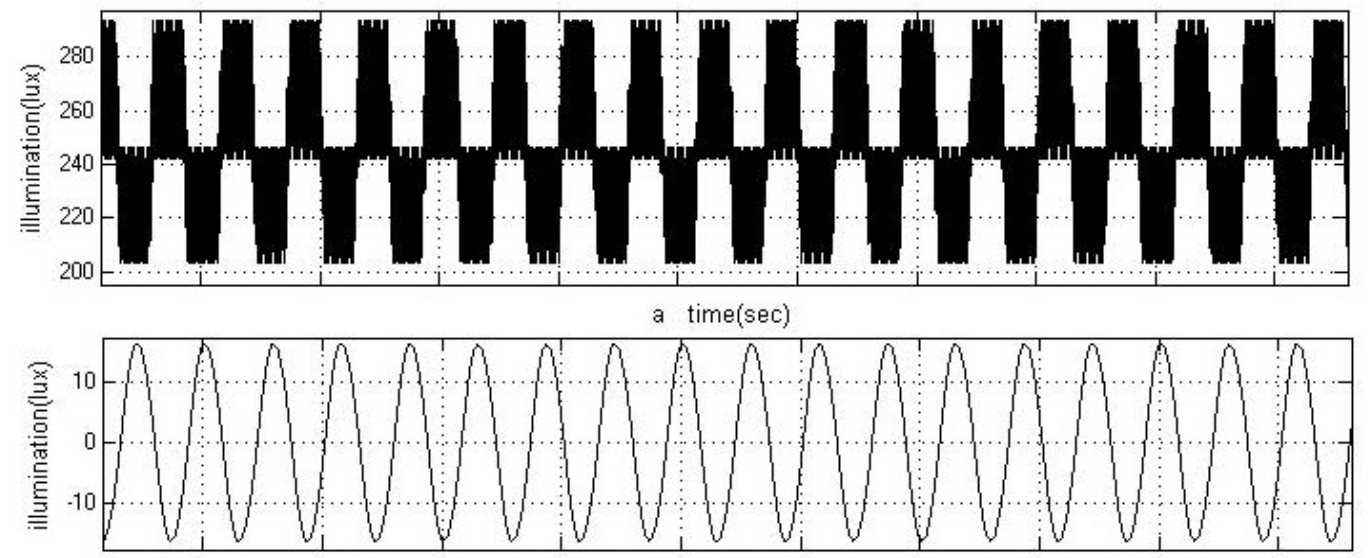

b time(sec)



Fig. 8: Result3

\section{ACKNOWLEDGMENT}

I would like to thank Nayana P Shetty and Vishnu Prasad V Bhat for internal and external guidance of project

\section{REFERENCES}

[1]. Guilherme Piazentini Colnago , Jose Rubens Macedo, Jose Luiz de Freitas Vieira,Dept. Electrical Engineering Implementation of a light Flickermeter in a low cost embedded system IET Sci. Meas. Technol., 2015, Iss. 4, pp. 522-531 doi: 10.1049/iet smt.2014.0202

[2]. Wilkins, A.J., Nimmo-Smith, I., Slater, A.I., Bedocs, L. 'Fluorescent lighting, headaches and eyestrain', Light. Res. Technol., 1989, 21, (1), pp. 11-18, doi: 10.1177/096032718902100102

[3]. Bharat, B.'Arc furnace flicker measurements and control', IEEE Trans. Power Deliv., 1993, 8, (1), pp. 400-410, doi: 10.1109/61.180362

[4]. Wilkins, A., Veitch, J., Lehman, B. 'LED lighting flicker and potential health concerns: IEEE standard PAR1789 update', Atlanta, USA, September 2010, pp. 171-178, doi: 10.1109/ECCE.2010.5618050

[5]. Wang, C.S., Devaney, M.J. 'Incandescent lamp flicker mitigation and measurement', IEEE Trans. Instrum. Meas., 2004, 53, (4), pp. 10281034, doi: 10.1109/TIM.2004.831131

[6]. Gallo, D., Landi, C., Langella, R., Testa, A. 'On the use of the flickermeter to limit low-frequency interharmonic voltages', IEEE Trans. Power Deliv., 2008, 23, (4), pp. 1720-1727, doi: 10.1109/ TPWRD. 2008.2002842

[7]. Macedo, J.R., Simonetti, D.S.L.'An'alise de desempenho do flickermeter na presenc sa dc componentes inter-harm`onicas', Controle Autom., 2012, 23, (4), pp. 508-519, doi: 10.1590/ S0103-17592012000400010

[8]. Colnago, G.P., Vieira, J.L.F., Sousa, G.C.D., Macedo, J.R.'Real time power quality monitoring system according to new brazilian regulation policies, Proc. 14th Int. Conf. on Harmonics and Quality of Power (ICHQP 2010), Bergamo, Italy, September 2010, pp. 1-8, doi: 10.1109/ICHQP.2010.5625313

[9]. Tayjasanant, T., Wencong, W., Li, C., Xu, W. 'Interharmonic-flicker curves', IEEE Trans. Power Deliv., 2005, 20, (2), pp. 1017-1024, doi: 10.1109/TPWRD.2004.838639

\section{BIOGRAPHIES}

Roshani Supriya B N received the B.E degree in Electronic and Communication Engineering at University of VTU, India in 2014. She is currently pursuing the M.Tech degree in the Electrical and Electronic Engineering Department, University of VTU.

Nayana P Shetty received M.Tech degree in Power and Energy Systems at NITK, Surathkal, India in 2006. She is currently pursuing the Ph.D. degree at University of VTU and also the Associate Professor at University of NMAMIT, Nitte, India 2016. 